\title{
Mechanism and Inhibition Efficiency of Biomass Tetraselmis chuii sp. on Carbon Steel Corrosion in The Environment under The Conditions of Oil Wells
}

\author{
Yayan Sunarya*, Heli Siti H. Munawaroh, Gun Gun Gumilar \\ Chemistry Study Program, Indonesian University of Education, Bandung \\ *Corresponding Author: yayan_sunarya@upi.edu
}

Received: November,16,2018 /Accepted: June,06,2020 doi: 10.24252/al-kimiav8i1.7230

\begin{abstract}
Corrosion control on petroleum pipe wells can only be done through the addition of corrosion inhibitors. In this study, the corrosion inhibitors studied were sourced from marine microorganisms, namely the type of microalgae Tetraselmis chuii sp. The aim to be achieved in this study was to determine the mechanism and efficiency of inhibition of the extraction of microalgae biomass in corrosion of carbon steel in an environment of p etroleum conditions. To achieve this goal, a potentiodynamic polarization method (Tafel extrapolation) was used and the Electrochemistry Impedance Spectroscopy (EIS) method used the galvanostat -potentiostat device (Voltalab 40, PGZ 301). The results obtained from this study indicate that API $5 L$ X65 carbon steel in the petroleum environment is very significantly corroded, caused by acidic media derived from acetic acid and dissolved $\mathrm{CO}_{2}$. The inhibition ability of the Tetraselmis chuii sp. Biomass extract. in line with the increasing extraction concentration reaching optimum at a concentration of 250 ppm with inhibition efficiency reaching $70 \%$. The mechanism of inhibition takes place through the formation of a protective layer adsorbed on the surface of carbon steel. The protective membrane formed is uneven and tends to be porous.
\end{abstract}

Keyword: corrosion inhibitor, EIS/Tafel, microalgae, petroleum oil, Tetraselmis chuii sp.

\section{INTRODUCTION}

In petroleum mining, $\mathrm{CO}_{2}$ saturated water is pumped into wells production to reduce viscosity and facilitate oil to get out easily (Seal S., et. Al. 2000). The crude oil produced contains inorganic salts (chlorides, sulfates and carbonates), organic acids $\left(\mathrm{CH}_{2} \mathrm{O}_{2}\right.$, $\mathrm{C}_{2} \mathrm{H}_{4} \mathrm{O}_{2}$, and $\left.\mathrm{C}_{3} \mathrm{H}_{6} \mathrm{O}_{2}\right)$, and acidic gases $\left(\mathrm{CO}_{2}\right.$ and $\left.\mathrm{H}_{2} \mathrm{~S}\right)$, so that when mixed with water at high temperatures being a very corrosive medium for carbon steel pipes used (Obeyesekere, et.al, 2000).

The presence of $\mathrm{CO}_{2}$ in the media results in acidic media and triggers the occurrence of hydrogen evolution (Seal, et. Al., 2000). Although dissolved $\mathrm{CO}_{2}$ can react with $\mathrm{Fe}$ to form $\mathrm{FeCO}_{3}$ adsorbed on the surface of carbon steel and is passive, but corrosion cannot be avoided because in the media there are organic acids and chloride ions, where the species are very aggressive to be able to break $\mathrm{FeCO}_{3}$ passive membranes (K. Videm, 2000; B. Hedges and L. Mc. Veigh, 1999).

Corrosion on the external part of the pipe could be overcame by coating or cathodic protection, but corrosion on the internal part can only be overcame by adding adsorbed type inhibitors (adsorbates), namely a chemical that is added to the corrosive environment in very little amount to control corrosion through the mechanism of forming a protective thin membrane on the surface of the internal part of the pipe (Sunarya et al., 2016).

The development of corrosion inhibitors is directed at heteroatom organic compounds containing nitrogen, sulfur, oxygen, or phosphorus. The inhibitory power of 
these atoms is: $\mathrm{P}>\mathrm{S}>\mathrm{N}>\mathrm{O}$ (Raicheva, et. al., 1992). The inhibitory ability of organic compounds is based on affinity for metals. There are three groups of organic compounds that have the potential as metal corrosion inhibitors, namely: (1) amine compounds, (2) heterocyclic nitrogen compounds, and (3) compounds containing mercapto, phosphorus, amide or thiocarbamide groups (Şahin and Bilgiç, 2003; Hesham T.M, et.al., 2016; Aprael S. Yaro, et.al., 2013).

The development of corrosion inhibitors from carbon compounds requires an understanding of the relationship between structure and adsorption properties and their mechanisms because the adsorption properties depend on the structure and electronics of inhibitor molecules, such as functional groups, steric factors, electron densities, and donor orbital characters (Ramachandran et.al., 1999; Popova, et. al., 2004; Hamdy and Nour, 2013). Corrosion inhibitors suitable for protecting petroleum wells at low acidity and high temperatures are types of adsorbates, soluble in water and oil but do not stabilize emulsions, are safe for the environment and are easily obtained at competitive prices (Tomoe, Y. and Shimizu, M ., 2000).

Based on the results of the study, it is known that many functional groups of nitrogen-containing carbon compounds have high corrosion inhibition activity, especially amine compounds. Amine compounds are found in microalgae as a constituent of cell walls (Kamal dan Sethuraman, 2012). According to Greene, et al. (2006), in microalgae there are various active sites which have the potential to bind to metals, including functional groups amine, amide, imidazole, hydroxyl, phosphate, thiol, and thioether.

Microalgae are the most primitive plant-sized cellular organisms commonly known as phytoplankton. This organism is a primary producer of water that is capable of photosynthesis like high-level plants. Microalgae play an important role in food webs in marine waters and are organic matter in marine sediments (Kawaroe et al., 2010). Therefore in this study, it will be directed at certain microalgae biomass as an alternative material for metal corrosion inhibitors in the environment according to the conditions of petroleum production wells.

\section{RESEARCH METHODS}

\section{Materials and Tools}

This research uses acetone, natrium chloride $(\mathrm{NaCl})$, acetate acid $\left(\mathrm{CH}_{3} \mathrm{COOH}\right)$, sodium acetate $\left(\mathrm{CH}_{3} \mathrm{COOHNa}\right)$, Tetraselmis chuii sp., distillate water, and methanol. Then, the tools functioned are carbon steels and electrode (platinum).

\section{Procedures}

\section{Preparation of working electrodes}

Carbon steel samples are taken from the type of American Petroleum Institute (API) 5L grade X65 with the follow ing compos ition (in percent): 


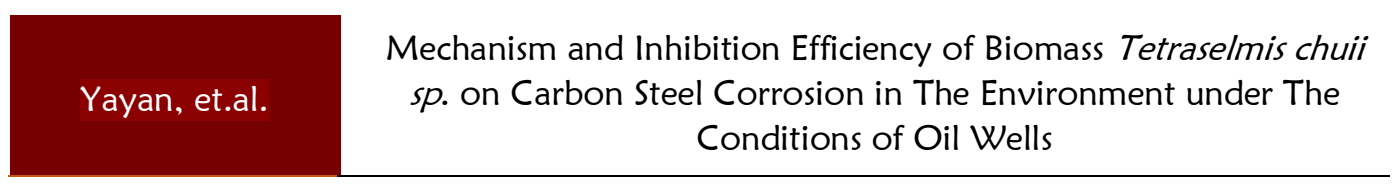

Tabel 1 Composition of samples

\begin{tabular}{lllllllllll}
\hline $\mathrm{C}$ & $\mathrm{Si}$ & $\mathrm{S}$ & $\mathrm{P}$ & $\mathrm{Mn}$ & $\mathrm{Ni}$ & $\mathrm{Cr}$ & $\mathrm{Cu}$ & $\mathrm{W}$ & $\mathrm{A}$ & $\mathrm{Fe}$ \\
\hline 0,074 & 0,288 & 0,007 & 0.015 & 1.535 & 0.013 & 0.022 & 0.005 & 0.003 & 0.028 & 97.933 \\
\hline
\end{tabular}

Working electrodes were made by cutting the API-5L-X65 sample, turning into a diameter of $1.4 \mathrm{~cm}$ and a length of $2 \mathrm{~cm}$, connected with copper wire, and coated with epoxy resin to obtain a surface area of $1.5 \mathrm{~cm}^{2}$. Before being used as a working electrode, the electrode surface was smoothed with sandpaper (grade 400 to 1200), washed with distillate water and acetone, then dried.

\section{Preparation of the test solution}

The test solution is made by dissolving a certain amount of Merck quality chemicals p.a. into the distillate water, as follows:

The test solution ( $\mathrm{pH} 3.0$ 0.05) was prepared by dissolving $11.7 \mathrm{~g} \mathrm{NaCl}$ plus concentrated $\mathrm{CH}_{3} \mathrm{COOH}$ and $0.146 \mathrm{~g} \mathrm{CH}_{3} \mathrm{COONa}$ into distillate water up to 1 liter volume (the composition of the media according to the conditions of the oil production well earth).

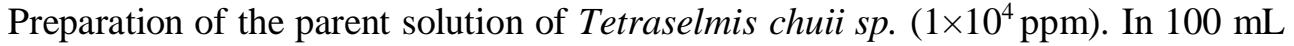
of distillate water methanol extracted from Tetraselmis chuii $s p$. as much as $1.0 \pm 0.003 \mathrm{~g}$.

\section{Testing Procedure}

Poured into $250 \mathrm{ml}$ electrochemical cell $\mathrm{NaCl}$ solution, continuously bubbled with $\mathrm{CO}_{2}$ at a pressure of $0.25 \pm 0.05 \mathrm{~atm}$ and stirred with a magnetic stirrer at a speed of 400 $\mathrm{rpm}$. The working electrode (carbon steel), the reference electrode (saturated calomel electrode, SCE), and the auxiliary electrode (platinum) dipped in the test solution and connected to the potentiostat from Radiometer ${ }^{\circledR}$ (Voltalab PGZ 3O1). Before being measured, the cell is left for 1 hour so that the carbon steel / media interface reaches a steady state. Tetraselmis chuii sp. Concentration tested $0.01 \mathrm{mM}$ and the temperature of the system is controlled by a thermostat. Output data from the measurement results are processed using the Voltamaster program 4 version.

In the measurement with the EIS, the sine wave signal is applied to disrupt the system are generated from AC potential with the amplitude of $10 \mathrm{mV}$ (ASTM G3, 1989) and a frequency range from $100 \mathrm{kHz}$ applied to $10 \mathrm{mHz}$. In polarization measurements, the applied DC potential is $\pm 50 \mathrm{mV}$ relative to the corrosion potential value. The polarization curve is recorded with a constant sweep rate at $0.5 \mathrm{mV} . \mathrm{s}-1$ (ASTM G5, 1987).

The results of the potentiodynamic polarization curve were extrapolated by the Tafel technique to obtain the corrosion potential, Tail $(\mathrm{mV})$, polarization resistance, $\operatorname{Rp}\left(\Omega . \mathrm{cm}^{2}\right)$, anodic constant, $\beta_{\mathrm{a}}$ and cathodic, $\beta_{\mathrm{c}}\left(\mathrm{mV} \cdot \mathrm{dec}^{-1}\right)$. Based on these values the corrosion current density, $I_{\text {corr }}\left(\Omega\right.$ A.cm $\left.{ }^{-2}\right)$ is determined by equation 1 and the corrosion rate, $\mathrm{V}_{\text {corr }}\left(\mathrm{mm} \cdot \mathrm{y}^{-1}\right)$ from the equation 2 


$$
\begin{aligned}
& I_{k o r}=\frac{\beta_{a} \cdot \beta_{c}}{2,303\left(\beta_{a}+\beta_{c}\right)} \frac{1}{R_{p}} \\
& V_{k o r}=0,00327 \frac{A_{r}}{n \rho} I_{k o r}
\end{aligned}
$$

$A_{r}$ is the relative atomic mass of metal, $n$ is the number of electrons involved in corrosion, and $\rho$ is the density of the metal. Determination of inhibition efficiency (\% EI) is based on corrosion current density, $I_{\text {corr }}$ according to equation 3.

$$
E I(\%)=\left(1-\frac{I_{\text {kor }}^{I w h}}{I_{\text {kor }}^{0}}\right) \times 100
$$

The impedance spectra from EIS measurements are expressed in the form of Nyquist, which expresses the relationship between imaginary impedance, $Z i_{(w)}$ as a function of real impedance, $Z r_{(w)}$. Furthermore, the spectra are processed by circular regression to obtain the resistance value of the solution $\left(R_{s}\right)$, charge transfer resistance $\left(R_{c t}\right)$, and multiple layer capacitance $\left(\mathrm{C}_{\mathrm{dl}}\right)$.

\section{RESULT AND DISCUSSION}

\section{Measurement of Potentiodynamic Polarization}

Based on the measurement of potentiodynamic polarization, the relationship between corrosion potential and corrosion current is obtained, which is then processed by the Tafel extrapolation technique to produce a graph as shown in Figure 1. Based on the graph it can be seen corrosion potential, $E_{c o r r}$, corrosion current density, $I_{c o r r}$, Cathodic Tafel constant, $\beta_{c}$ and the anodic Tafel constant, $\beta_{a}$, and the corrosion rate carbon steel in the test solution, $V_{\text {corr }}$. Data from extrapolation from Tafel are presented in table 2

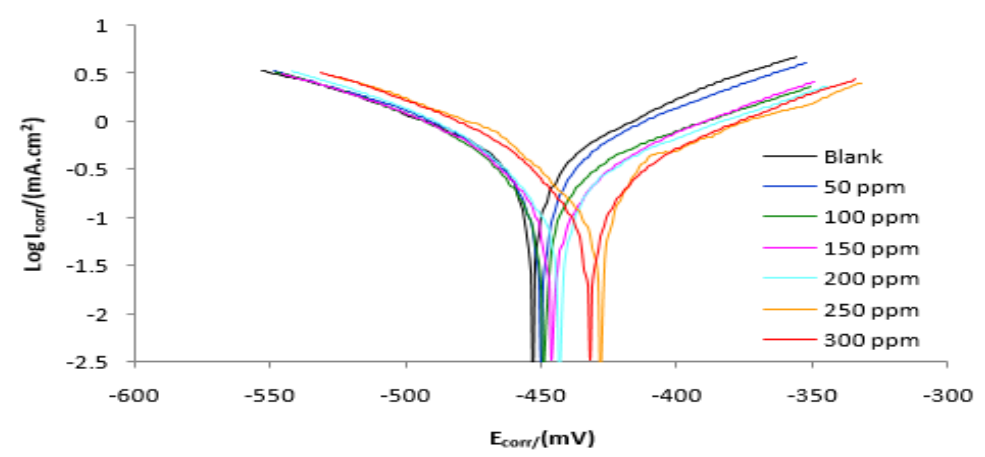

Figure 1. Corrosion potential and the logarith $m$ of corrosion current density for carbon steel in the test media with and without Tetraselmis chuii sp.

Al-Kimia|Volume 8 Nomor 1202013 
Table 2. Parameters of corrosion of carbon steel in the test solution and potential inhibition of the methanol extract of Tetraselmis chuii sp.

\begin{tabular}{llllll}
$C_{\text {inh }} /(\mathrm{ppm})$ & $E_{\text {corr }} /(\mathrm{mV})$ & $\square_{a} /(\mathrm{mV} / \mathrm{dec})$ & $\square_{c} /(\mathrm{mV} / \mathrm{dec})$ & $I_{\text {corr }} /\left(\square \mathrm{A} / \mathrm{cm}^{2}\right)$ & $V_{\text {corr }} /(\mathrm{mm} / \mathrm{y})$ \\
\hline- & -454.3 & 110.7 & 135.6 & 0.7764 & 8.9992 \\
50 & -450.3 & 109.8 & 122.6 & 0.6013 & 6.9766 \\
100 & -448.6 & 105.9 & 92.1 & 0.3622 & 4.2021 \\
150 & -444.9 & 98.2 & 88.3 & 0.3168 & 3.6761 \\
200 & -443.4 & 95.1 & 84.1 & 0.2596 & 3.0122 \\
250 & -432.3 & 94.9 & 81.3 & 0.2119 & 2.4580 \\
300 & -429.9 & 93.2 & 77.2 & 0.1992 & 2.0714 \\
\hline
\end{tabular}

The corrosion rate of carbon steel in the test solution $(0.2 \mathrm{M} \mathrm{NaCl}$ solution saturated with $\mathrm{CO}_{2}$ gas bubbling and its $\mathrm{pH}$ is controlled by an acetate buffer of $3.0 \pm 0.05$ ) reaching $9 \mathrm{~mm}$ per year. This means that the corrosion of carbon steel surface by a test solution in one year is $9 \mathrm{~mm}$ thick. Addition of Tetraselmis chuii to the test solution reduced the corrosion rate of carbon steel to $2.07 \mathrm{~mm}$ per year. The inhibition ability of Tetraselmis chuii on corrosion of carbon steel in the test solution is shown in Figure 2.

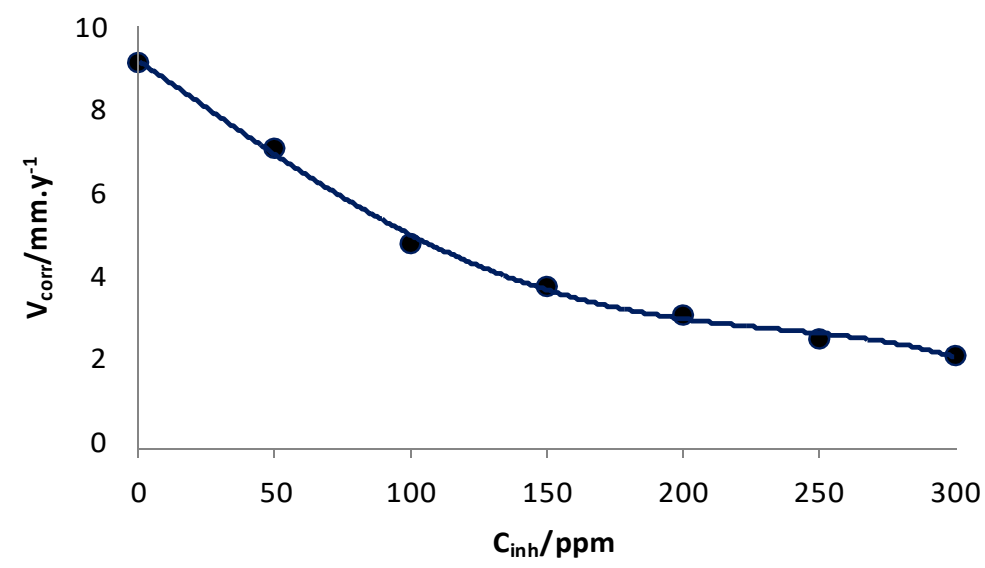

Figure 2. Decreasing the corrosion rate of carbon steel in a test solution by Tetraselmis chuii sp

The decrease in corrosion rate with the presence of Tetraselmis chuii indicates that the addition of Tetraselmis chuii to the test solution can reduce the energy level of the outer electrons on the surface of carbon steel which results in a decrease in the metal's outer electrons (Sato, 1987), so that the corrosion rate carbon steel decreases. In other words, the formation of $\mathrm{Fe}^{2+}$ ions on the surface of carbon steel is inhibited by the presence of microalgae.

Before Tetraselmis chuii was added to the solution, value of $E_{\text {corr }}$, was $-454.3 \mathrm{mV}$. After addition, the corrosion potential value shifts towards a more positive direction, as in Figure 3. This shows that the presence of Tetraselmis chuii lowers the energy level of the 
electron by shifting the corrosion potential in a more positive direction. This shift shows that the inhibition mechanism of Tetraselmis chuii through inhibition of anodic oxidation process by forming a protective layer on the metal surface. Decreasing electron energy levels on carbon steel surfaces give the opportunity for molecules extracted from Tetraselmis chuii to act as Lewis bases or van der Walls styles (Singh, et.al., 2016; AlOtaibi, 2014).

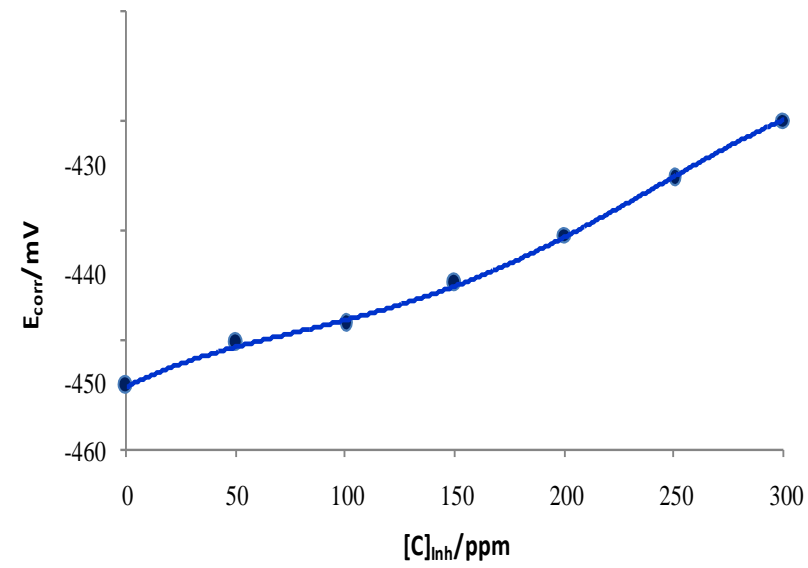

Figure 3. Effect of the addition of Tetraselmis chuii to the corrosion potential of carbon steel

Observing the values of anodic Tafel $\left(\beta_{\mathrm{a}}\right)$ and cathodic $\left(\beta_{\mathrm{c}}\right)$ which are constants, the Tetraselmis chuii can reduce both the values $\beta_{\mathrm{a}}$ and $\beta_{\mathrm{c}}$. This indicates that the corrosion inhibition mechanism, other than through anodic processes, also through increasing the potential barrier energy to inhibit the hydrogen evolution reaction in the cathodic process, so that the electron transfer rate from the carbon steel surface to the $\mathrm{H}^{+}$ions is inhibited or by binding $\mathrm{H}^{+}$ions by extract Tetraselmis chuii (hydrogen scavenger), consequently the rate of formation of $\mathrm{H}_{2}$ gas in the solution is inhibited. Thus, Tetraselmis chuii is classified as a mixed type inhibitor.

The presence of Tetraselmis chuii in the test solution decreases the corrosion density current value, $I_{\text {corr }}$. The more concentration of Tetraselmis chuii is added, the smaller the value of $I_{\text {corr }}$, so that the corrosion rate of carbon steel decreases. The optimal concentration achieved by Tetraselmis chuii in inhibiting corrosion of carbon steel is approximately 250 ppm with inhibition efficiency reaching $70 \%$, as shown in figure 4 . 


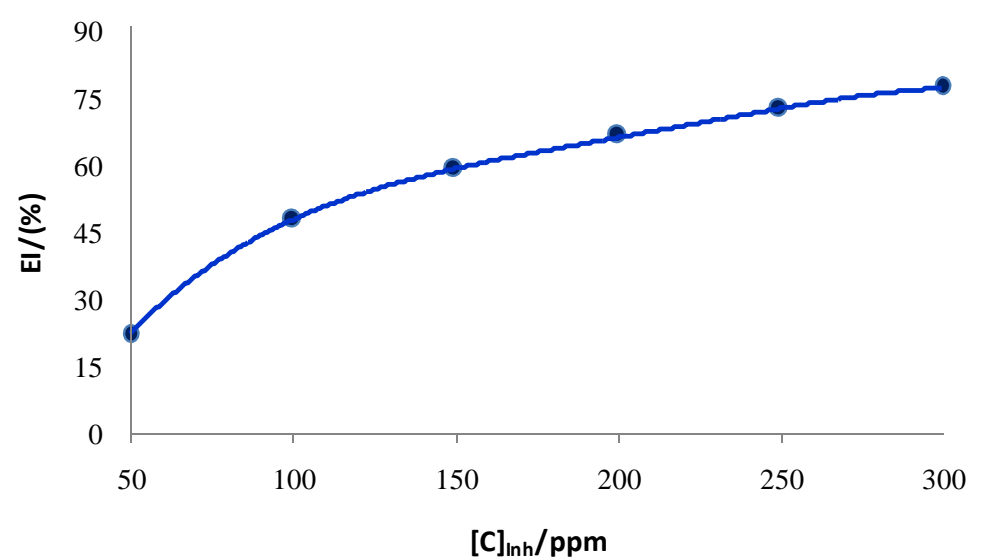

Figure 4. Relationship between inhibition effic iency and chuii Tetraselmis concentration based on the results of polarization measurements

\section{Impedance Measurement}

Measurement data using the EIS method in the form of impedance spectra are expressed in the form of a Nyquist diagram, this diagram states the relationship between real impedance, $Z_{\mathrm{r}}$ and imaginary impedance, $-Z_{\mathrm{i}}$ (Figure 5). Furthermore, the data is processed using a circular regression technique to obtain electrochemical parameters in the form of solution resistance, $\mathrm{R}_{\mathrm{s}}$, charge transfer resistance, $\mathrm{R}_{\mathrm{ct}}$, and double-layer capacitance, $\mathrm{C}_{\mathrm{dl}}$, presented in Table 2 . The form of an impedance diagram in the form of semi-circular, which indicates that the carbon steel corrosion process is controlled by the transfer of cargo. However, the impedance diagram is not really semi-circular, this is caused by the presence of dispersion at high frequencies.

The presence of Tetraselmis chuii in the relative test solution does not change the resistance of the solution. That is, Tetraselmis chuii is not an ionic compound but in the form of a polar molecule so that the solution resistance or electrical conductivity is relatively constant. On the other hand, the addition of Tetraselmis chuii can increase the charge transfer

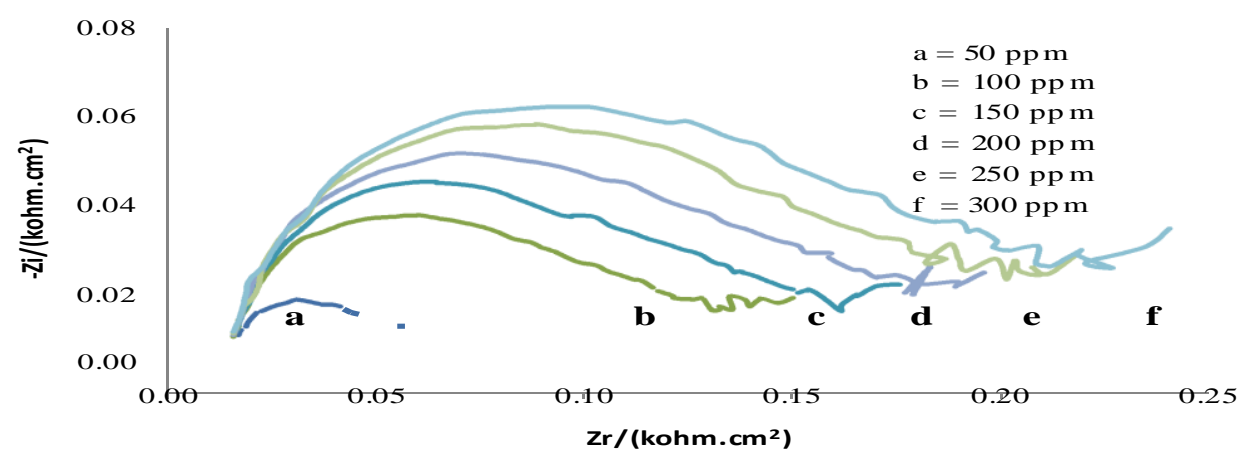

Figure 5. Carbon steel impedance spectra in the test solution with and without Tetraselmis chuii sp. at various concentrations

Al-Kimia|Volume 8 Nomor 1202016 
Resistance on carbon steel surfaces, which results in the reduction of hydrogen ions and the oxidation process of Fe atoms at the metal interface and the solution becomes inhibited, so the corrosion rate of carbon steel decreases

Table 3. The electro-kinetic parameters of carbon steel in the test solution with and without Tetraselmis chuii sp.

\begin{tabular}{llll}
\hline $\mathrm{C}_{\mathrm{Inh}} /(\mathrm{mM})$ & $\mathrm{R}_{\mathrm{S}} /\left(\square . \mathrm{cm}^{2}\right)$ & $\mathrm{R}_{\mathrm{ct}} /\left(\square . \mathrm{cm}^{2}\right)$ & $\mathrm{C}_{\mathrm{dl}} /\left(\square \mathrm{F} / \mathrm{cm}^{2}\right)$ \\
\hline- & 13,54 & & 194,6 \\
50 & 12,38 & 110,30 & 175,0 \\
100 & 12,00 & 144,60 & 162,5 \\
150 & 11,60 & 177,60 & 151,5 \\
200 & 11,48 & 210,60 & 149,4 \\
250 & 11,23 & 238,20 & 135,8 \\
300 & 11,11 & 278,60 & 124,2 \\
\hline
\end{tabular}

Double-layer capacitance is obtained at the maximum frequency, $f_{\text {maks }}$, ie when the value of the imaginary component of the impedance reaches its maximum, $-Z_{i(\max )}$, according to the following equation (Loveday, 2004):

$$
f\left(-Z_{i m a k s}\right)=\frac{1}{2 \pi C_{d l} R_{c t}}
$$

The carbon steel response to impedance has changed dramatically in the presence of Tetraselmis chuii and its frequency has increased with increasing it concentration. As a result, the value of double layer capacitance is significantly reduced. The decrease in value can be caused by the presence of Tetraselmis chuii adsorption on the surface of carbon steel to form a protective layer which is insoluble so that there is a decrease in the local dielectric constant.

\section{Equivalent electrical circuit model at the interface}

To interpret the electrical properties at the interface between carbon steel and the test solution can be studied through the Zview program from Scribner Associates. This is done by means of curve fitting the impedance spectra measurement results with impedance spectra curve simulation models developed equivalence electrical circuits (Loveday 2004). Based on the simulation results of electric circuit models it is known that the interface of carbon steel with the test solution without the presence of Tetraselmis chuii has an electric circuit model as shown in figure 6 (a). 


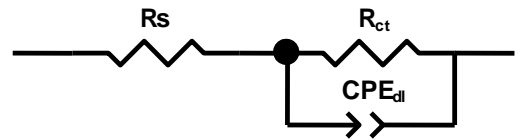

(a)

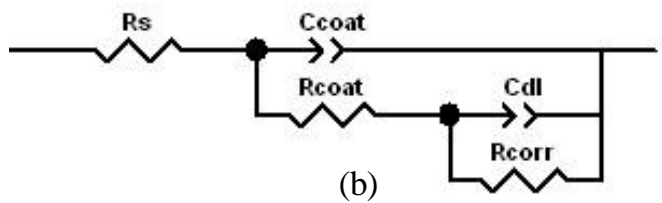

(b)

Figure 6: Electrical circuit model equivalent to the carbon steel interface and test solution.

(a) Without microalgae; (b) contains microalgae.

The electrical circuit model in Figure 6.a consists of solution resistance, charge transfer resistance, and multiple layer capacitances, $\mathrm{CPE}_{\mathrm{dl}}$, at the metal interface and solution. Such circuit models show that the corrosion rate of carbon steel is controlled by the rate of charge transfer reaction. Symptoms like this are commonly found when a metal is dipped in a solution, where a protective layer has not been formed. The presence of Tetraselmis chuii changes the circuit model as shown in figure 6 (b), and applies to all Tetraselmis chuii concentrations added to the solution. The model indicates that on a carbon steel surface a protective layer is formed from the extract of methanol Tetraselmis chuii which is imperfectly adsorbed with layer resistance and double layer capacitance indicated by $\mathrm{R}_{\text {coat }}$ and $\mathrm{C}_{\text {coat. }}$. Imperfection is indicated by the presence of multiple electrical layer capacitances between the protective layer and the carbon steel surface.

Based on the equivalent electrical circuit model it can be stated that Tetraselmis chuii can inhibit the corrosion of carbon steel in the test solution by forming a protective layer on the surface of carbon steel. However, the protective layer formed is not perfect because there are still a number of pores that can be penetrated by the species in the solution so that the inhibitory efficiency is less effective.

\section{CONCLUSIONS}

The corrosion rate of API-5L-X65 carbon steel in a solution that is in accordance with the conditions of petroleum production wells reaches a thickness of $9 \mathrm{~mm}$ per year. Addition of Tetraselmis chuii sp. into the test solution can reduce the corrosion rate to 2.07 $\mathrm{mm}$ per year with a percent efficiency of inhibition of $70 \%$ for the concentration of Tetraselmis chuii $250 \mathrm{ppm}$. Tetraselmis chuii is a mixed type inhibitor. The mechanism of inhibition is through the formation of protective layers that tend to be still porous.

\section{ACKNOWLEDGMENTS}

We thank to the Ministry of Research, Technology and Higher Education for funding research funding through the Higher Education Applied Research Program until this article can be presented in a seminar.

\section{REFERENCES}

Al-Otaibi, M.S., Al-Mayouf, A.M., Khan, M., Mousa, A.A., Al-Mazroa, S.A., Alkhathlan, H.Z., (2014): Corrosion inhibitory action of some plant extracts on the corrosion of mild steel in acidic media, Arab. J. of Chem., 7, 340-346. 
Ambrish Singh, Ishtiaque Ahamad, Mumtaz A. Quraishi, (2016): Piper longum extract as green corrosion inhibitor for aluminium in $\mathrm{NaOH}$ solution, Arab. J. of Chem. 9, S1584-S1589.

Aprael S. Yaro, Anees A. Khadom, Rafal K. Wael, (2013): Apricot juice as green corrosion inhibitor of mild steel in phosphoric acid, Alexan. Engin. J. 52, 129-135.

ASTM G-3 (1989): Standard practice for conventions applicable to Electrochemical Impedance Measurement in corrosion testing, Annual Book of ASTM Standard, Metal Test Methods and Analytical Procedures, American Society for Testing and Materials.

ASTM G-5 (1987): Standard practice for making potentiodynamic anodic polarization measurements convention applicable to electrochemical measurement in corrosion testing, Annual Book of ASTM Standard, Metal Test Methods and Analytical Procedures, American Society for Testing and Materials.

Hamdy, A. and Nour Sh. El-Gendy, (2013): Thermodynamic, adsorption and electrochemical studies for corrosion inhibition of carbon steel by henna extract in acid medium, Egyp. J. of Petrol. 22, 17-25

Hesham T.M. Abdel-Fatah, Salah A.M. Rashwan, S.M. Abd El Wahaab, Aliaa A.M. Hassan, (2016): Effect of Tryptophan on the corrosion behavior of low alloy steel in sulfamic acid., Arab. J. of Chem. 9, S1069-S1076

Ismail, K.M.,(2007): Evaluation of cysteine as environmentally friendly corrosion inhibitor for copper in neutral and acidic chloride solutions, Electrochim. Acta, 52, 7811-7819

Kamal, C., Sethuraman, M.G., (2012): Spirulina platensis - A novel green inhibitor for acid corrosion of mild steel, Arab. J. of Chem., 5, 155-161

Kiani, M. A., Mousavi, M. F., Ghasemi, S., Shamsipur, M., dan Kazemi, S. H., (2008): Inhibitory effect of some amino acids on corrosion of $\mathrm{Pb}-\mathrm{Ca}-\mathrm{Sn}$ alloy in sulfuric acid solution, Corros. Sci., xxx (2008) xxx-Xxx, 1-11.

Laamari, M.R., Benzakour, J., Berrekhis, F., Derja, A., Villemin, D., (2011): Adsorption and corrosion inhibition of carbon steel in hydrochloric acid medium by hexamethylenediaminetetra(methylene phosphonic acid), Arabic J. Chem., xxxXXX.

Loveday, D., Peterson, P., dan Rodgers, B., (2004): Evaluation of Organic Coatings

with Electrochemical Impedance Spectroscopy: Fundamentals of Electrochemical Impedance Spectroscopy, Analytical Series, JCT CoatingsTech. 
Raicheva, S.N., Aleksiev, B.V., Sokolova, E.I. (1993): The Efeect of The Chemical Structure of Some Nitrogen and Sulphur-Containing Organic Compounds on Their Corrosion Inhibiting Action, Corrosion Science, 34(2), 343-350.

Şahin, M., dan Bilgiç, S., (2003): The inhibition effects of some heterocyclic nitrogenous compounds on the corrosion of the steel in CO2-saturated $\mathrm{NaCl}$ solutions, J. Anti-Corros. Method and Matter., 50 (1), 34-39.

Sato, Norio, (1987): Some concepts of Corrosion Fundamentals, Corrosion Science, $27(5), 421-433$.

Scribner Associates, Inc., Zview Program, www.scribner.com

Sunarya, Y., Munawaroh, H. S. Halimatul, Mushapa, I. and Tristiani, D., (2016): The Mechanism And Efficiency Of Inhibition Of Galangal Rhizome (Alpinia Galanga L.) On The Corrosion Of Carbon Steel In An Environment Appropriateness To Conditions Of A Petroleum Well, ARPN J. of Eng. and App. Sci., 11, 22, 2016.

Sunarya, Y., Radiman, C.L., Sadijah A., B. Bundjali (2007), Amino acids as Corrosion Inhibitor for Carbon steels., Proceeding of International Conference on Mathematics and Natural Sciences/ICMNS, November 29-30, 2006, Bandung, p $623-626$. 